\title{
INTERACTION OF VULCANIZATION FACTORS DURING CONTINUOUS RUBBER EXTRUSION
}

\author{
Nina Djapic ${ }^{1^{*}}$ Ivan Ikonov² Vitomir Antonic ${ }^{3}$ \\ ${ }^{1}$ University of Novi Sad, Technical faculty "Mihajlo Pupin", Zrenjanin, Serbia \\ ${ }^{2}$ Novkabel AD, Industrijska bb, Novi Sad, Serbia \\ ${ }^{3}$ Technical School "Kosta Abrasevic", Sabac, Serbia
}

The objective of this study was to investigate the interaction factors during the technological process of rubber-insulated conductor's production with continual extrusion process. Rubber used for the insulation was ethylene-propylene copolymer. The reticulation inducers were different peroxides. The technological process consisted of conductor's coating with elastomer, through the continual vulcanization tube under steam pressure. The changes of vulcanization process variables: pressure and speed (vulcanization time) influence the elastomer's mechanical properties, its tensile strength. The multiple and partial correlation study was used to estimate the effects of steam pressure and vulcanization time, during the continual vulcanization, on the rubber's insulation tensile strength. The experiment was carried out during the extrusion of the conductor for the specific product type (H05RN-F $\left.2.5 \mathrm{~mm}^{2}\right)$. It was concluded, by the results obtained, that for keeping the vulcanization quality at high level, required is to keep pressure constant and to change the vulcanization time during the extrusion process. Numerical results obtained showed that the choice of speed (vulcanization time) increases the elastomer's tensile strength, when the pressure is kept at constant level.

Key words: Vulcanization, Tensile strength

\section{INTRODUCTION}

For cable insulation widely is used ethylene-propylene copolymer (EPM), former abbreviation EPR (ethylene-propylene rubber) or EI4 according to DIN VDE 0282 part 1 , due to its dielectric strength, low aging rate and resistance to partial discharges [02, 01, 14]. The EPR can be mixed with peroxides during the pre-processing phase at low temperatures enabling a well-defined final product's quality which is the main characteristic for the final insulator mechanical properties.

The cable cross-linking technological process can be horizontal or vertical continual vulcanization [13, 15]. The polymer cross-linking is obtained by dry curing under high pressure in a tube filled with steam. Process begins in an extruder where the copper conductor is coated with the extruded EPR. Then the cable enters the heated part filled with steam. The cable obtained is then, cooled with cold water and left at ambient temperature. The most important phase during the technological process is taking part in the vulcanization tube where rubber gets its final mechanical properties. The changes that occur in the vulcanization tube induce changes in insulator's mechanical properties, heat resistance and aging characteristics [07]. The parameters that influence EPR final mechanical properties are: exposition time, steam temperature and cooling water flow rate. The vulcanization time is controlled by the production line speed. Technologists and engineers can change cable velocity in order to optimize the technological process.

A mathematical model was used in order to determine the insulator's tensile strength value in dependence of steam pressure (temperature) and vulcanization time during the continual vulcanization. The goal of all investigations was to define the occurrences and their characteristics during the technological process using a mathematical model $[18,11,04,05,10]$. In this investigation applied was the correlation theory: the multiple and partial correlation, in the analysis of the technological process. Investigated was the dependence of factors during the continual extrusion of products with rubber insulation [12]. Determined was the vulcanization regime during the extrusion process in order to obtain the desired product characteristics [03]. Under laboratory and production conditions prepared was rubber and its mixtures. The testing was done under the laboratory conditions. The analysis of the results obtained was done in order to determine the conditions and its accordance with the specified relevant regulations for the rubber mixtures [17]. After the comparison of the results obtained, the rubber production was achieved.

The aim of the work was to investigate the vulcanization parameters on the quality of rubber insulation and its tensile strength. The experiment was set under the working conditions based on the prepared plan.

\section{THEORETICAL PART}

The theoretical basis was mathematical statistics, the part: the Theory of correlation, specified as the multiple and partial correlation (1). The occurrence and characteristics of the elements investigated were influenced with several factors. There was one dependent and two independent variables. First was considered the linear relationship between them. Dependent variable was 
signed as $x_{1}$, the independent ones as $x_{2}$ and $x_{3}$, and their relations as $x_{1 i}, x_{2 i}, x_{3 i}(i=1,2,3)$. The simplest $x_{1}$ regression equation in dependence of $x_{2}$ and $x_{3}$ is in a form of:

$$
x_{1}=a_{1.23}+b_{12.3} x_{2}+b_{1.3 .2} x_{3}
$$

In a three-dimensional coordinate system it can be presented as the regression plane. When linear relationship is to be determined necessary is to keep $x_{3}$ constant, then the equation (1) is a straight line with a direction coefficient $b_{12.3}$, and when it is assumed that $x_{2}$ is constant, then the equation (1) is a straight line with the direction coefficient $b_{13.2}$. The $b_{12.3}$ and $b_{13.2}$ are partial regression coefficients characterizing these partial changes. From the theory of least squares the sum of squared deviations has the form:

$$
S_{1.23}^{2}=\frac{1}{n} \sum\left(a_{1.23}+b_{12.3} x_{2 i}+b_{13} x_{3 i}-x_{1 i}\right)^{2}
$$

when it reaches the minimum the system of normal equations is obtained and in general is:

$$
\begin{aligned}
& \sum x_{1 i}=a_{1.23} n+b_{12.3} \sum x_{2 i}+b_{13.2} \sum x_{3 i} \\
& \left.\sum x_{1 i} \cdot x_{2 i}=a_{1.23} \sum x_{2 i}+b_{12.3} \sum x_{2 i}{ }^{2}+b_{13.2} \sum x_{2 i} x_{3 i} 3\right) \\
& \sum x_{1 i} \cdot x_{3 i}=a_{1.23} \sum x_{3 i}+b_{12.3} \sum x_{2 i} \cdot x_{3 i}+b_{13.2} \sum x_{3 i}
\end{aligned}
$$

In order to obtain the necessary mathematical formulas for calculating the relative factors of the process it is necessary to introduce the signs which are:

- Linear correlation coefficient between $x_{1}$ and $x_{2}, x_{1}$ and $x_{3}, x_{2}$ and $x_{3}$ and are marked as $r_{12}, r_{13}, r_{23}$

- Arithmetic means are $\bar{x}_{1}, \overline{x_{2}}, \overline{x_{3}}$

- The standard deviation of the variables $x_{1}, x_{2}$ and $x_{3}$ are $s_{1}, s_{2}, s_{3}$

- A new variable is introduced in a form of the equation: $X_{1}=x_{1}-\bar{x}_{1}, X_{2}=x_{2}-x_{2}, X_{3}=x_{3}-x_{3}$ then the standard deviation of the variables is:

$$
\begin{aligned}
s_{1} & =\sqrt{\frac{1}{n} \sum x_{1 i}^{2}-\left(\frac{1}{n} x_{1 i}\right)^{2}} \\
s_{1}^{2} & =\frac{1}{n_{i}} \sum X_{1 i}^{2}=\frac{1}{n} \sum\left(x_{1 i}-\bar{x}_{1}\right)^{2}
\end{aligned}
$$

and identical follows for $s_{2}^{2}$ and $s_{3}{ }^{2}$ :

$$
r_{12}=\frac{\Sigma X_{1 i} \cdot X_{2 i}}{\sqrt{\left(\Sigma X_{1 i}^{2}\right)}\left(\Sigma X_{2 i}^{2}\right)}=\frac{\Sigma X_{1 i} \cdot X_{2 i}}{n \cdot s_{1} \cdot s_{2}}
$$

and can be written in a form (6):

$$
r_{12}=\frac{n \sum x_{1 i} \cdot x_{2 i}-\left(\sum x_{1 i}\right)\left(\sum x_{2 i}\right)}{\sqrt{\left[n \sum x_{1 i}^{2}-\left(\sum x_{1 i}\right)^{2}\left[n \sum x_{2 i}^{2}-\left(\sum x_{2 i}\right)^{2}\right]\right.}}
$$

Identical follows and for $r_{13}$ and $r_{23}$.

For $x_{r 1 i}(\mathrm{i}=1,2, \ldots \mathrm{n})$, the value $x_{1}$ is calculated with the equation (1) and then the $x_{1}$ standard estimation error with $x_{2}$ and $x_{3}$ is calculated from the residual dispersion equation and is:

$$
S_{1.23}=\sqrt{\frac{1}{n} \sum\left(x_{1 i}-x_{r_{1 i}}\right)^{2}}
$$

The coefficients of multiple correlations are:

$$
R_{1.23}=\sqrt{1-\frac{S_{1.23}^{2}}{s_{1}^{2}}}
$$

The coefficient of multiple determination is:

$$
R_{1.23}^{2}
$$

The partial-correlation coefficient between the $x_{1}$ and $x_{2}$, taking into account that $x_{3}$ is a constant, is:

$$
r_{12.3}=\frac{r_{12}-r_{13} \cdot r_{23}}{\sqrt{\left(1-r_{12}^{2}\right) \cdot\left(1-r_{23}^{2}\right)}}
$$

In the identical way calculated is $r_{13.2}$ and $r_{23.1}$.

Calculating the values from the above-mentioned equations obtained is a scholar approach in achieving the relevant values for the process validation and analysis.

Technological processes were done in two separate modes. One process was done in laboratory, the other under working conditions in the factory Novkabel, Novi Sad. Rubber mixture was made in laboratory, according to the recipe, on the laboratory mixer Brabender $\AA \mathrm{GmbH}$ \& Co KG. Mixing of the material in the mixing chamber was done by two horizontal rotors with protrusions. Rubber made was pressed in standard foils on hydraulic press "Belišće" with special accessories in order to determine the regime vulcanization-temperature (oC), time (s) and mechanical properties according to ISO 1421 [06]. From rubber foils cut were standard tubes with special tools in order to determine the breaking force and tensile strength. Breaking was done on testing machine Thueringer Industriewerk type WPM 2092, according to ISO 1421 [06]. After experiments done, obtained were results which permitted the characterization of the rubber mixture. The results obtained permitted the settlement of the experiment under working conditions on the production equipment: mixer for preparing the rubber mixture Werner \& Pfleiderer $\mathrm{GmbH}$, with the strainer for rubber rolling, choppers for cutting into strips and at the end the palletizing was done.

The conductor was produced on an extruder for extruding rubber, the horizontal line for vulcanization $\phi 120$ with tube for vulcanization with the length of $100 \mathrm{~m}$ and where the die length to die diameter was 15 . Next to the 
extruder, on the platform placed was pallet with rubber strips and the extruder was fed manually. The extruder working regime was programmed and it was possible to change the parameters automatically. Rubber mixture processing was done in the extruder and was extruded through compatible die with which the copper conductor isolation was done. Vulcanization of the isolation was done in the tube with steam. The continual vulcanization tube's length was $100 \mathrm{~m}$. In the cooling area, just before the exit from the tube, the product was cooled. The vulcanization regime was determined with steam pressure regarding temperature and retention time in the vulcanization tube area respecting the line velocity. The final product was coiled to the corresponding drum. The samples for the control were taken before storage.

\section{EXPERIMENTAL PART}

The experimental part was carried out according to the experimental plan and at several levels, according to the engineering experiment principle, as follows:

- the selection of the recipe for mixing rubber compounds with which the conductor insulation will be carried out

- the product selection which will be made under working conditions and on which the planned investigation will be performed

- providing the randomness and generality during the engineering experiment

- taking samples for testing the rubber insulation quality.

Under working conditions extruded was insulated conductor for the product H05RN-F with diameter of $2.5 \mathrm{~mm}^{2}$ (Figure 1). Isolation of insulated conductor was done with ethylene-propylene rubber, which was prior to application the subject of physical and chemical investigations. Working conditions induced the choice of randomization system, while the achievement of general principles was obtained with the choice of strip rubber mixture for feeding the extruder.

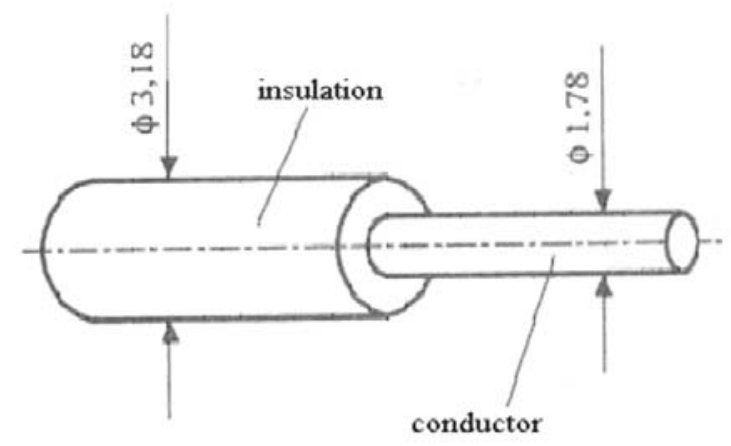

Figure 1: The sample for measurement
The experiment itself was located on extrusion line. The goal was to investigate tensile strength in dependence of vulcanization time which was changed on three levels and pressure which was changed on four levels. The experiments were done in triplicate for every level combination. Further, the pressure was chosen in a random way in the vulcanization pipes, and then the time was changed from one to three. After every time (velocity) change, the sample for quality investigations was taken. The tensile strength results obtained are depicted in Table 1.

Table 1: Vulcanization time and pressure measured

\begin{tabular}{|c|c|c|c|c|c|}
\hline \multirow{3}{*}{$\begin{array}{c}\text { Divided } \\
\text { slices R }\end{array}$} & \multirow{2}{*}{$\begin{array}{c}\text { Time } \\
t(s)\end{array}$} & \multicolumn{4}{|c|}{ Pressure (MPa) } \\
\cline { 3 - 6 } & & 1.7658 & \multicolumn{4}{|c|}{1.8639} & 1.9620 & 2.0601 \\
\cline { 3 - 6 } & & $\mathrm{p} 1$ & $\mathrm{p} 2$ & $\mathrm{p} 3$ & $\mathrm{p} 4$ \\
\hline \multirow{4}{*}{ I } & 46 & 5.89 & 6.29 & 6.90 & 6.44 \\
\cline { 2 - 6 } & 43 & 6.76 & 5.94 & 6.17 & 7.16 \\
\cline { 2 - 6 } & 40 & 6.05 & 7.18 & 6.67 & 7.02 \\
\hline \multirow{4}{*}{ II } & 46 & 6.87 & 5.91 & 6.51 & 6.49 \\
\cline { 2 - 6 } & 43 & 5.55 & 6.21 & 6.25 & 6.17 \\
\cline { 2 - 6 } & 40 & 6.21 & 6.19 & 6.00 & 6.96 \\
\hline \multirow{3}{*}{ III } & 46 & 6.21 & 5.91 & 6.92 & 7.26 \\
\cline { 2 - 6 } & 43 & 6.56 & 6.24 & 6.95 & 6.30 \\
\cline { 2 - 6 } & 40 & 6.62 & 6.38 & 6.38 & 7.23 \\
\hline
\end{tabular}

\section{RESULTS}

Samples analyzed were conductor's isolation with the length of $50 \mathrm{~mm}$. The tensile strength was calculated according to the equation: $\sigma=F / A, \mathrm{MPa}$, where $\mathrm{F}$ is the breaking force and $A$ is the cross-sectional area [09]. The inner and outer insulation diameter was measured with a microscope. The breaking force measurements were done on the testing machine Thüringer Industriewerk type WPM 2092. The investigations were done in accordance with ISO 1421 [06]. Results were systematized according to the chosen experimental model [11]. However, it was necessary to introduce standard assignments for the investigated factors in the equations (1) and (3). The results of tensile strength measurements, $\sigma$, $\mathrm{MPa}$, are presented in Table 2. Based on Table 1 formed was Table 2 with necessary sums for the system of normal equations (Table 2).

Thus, from the equation (1) and (3) is obtained:

$$
\sigma_{i}=a+b p_{i}+c t_{i}
$$

while the system of normal equations is:

$$
\begin{aligned}
& \sum \sigma_{i}=n a+b \sum p_{i}+c \sum t_{i} \\
& \sum \sigma_{i} p_{i}=a \sum p_{i}+b \sum p_{i}{ }^{2}+c \sum p_{i} t_{i} \\
& \sum \sigma_{i} t_{i}=a \sum t_{i}+b \sum p_{i} t_{i}+c \sum t_{i}{ }^{2}
\end{aligned}
$$


pi - the pressure in the tubes for vulcanization, MPa, [08];

ti - vulcanization time in the tubes for vulcanization, s;

then, it was possible to present the results:

- linear regression equation oi by pi and vi is in a form of (11), and the system of normal equations is in the form of (12). The solution for the system of equations was:

$$
\begin{aligned}
& a=1.5008761 \\
& b=2.5923697 \\
& c=0.00070946
\end{aligned}
$$

The searched linear regression equation was:

$$
\left.\sigma_{i}=1.5008761+2.5923697 p_{i}+0.00070946 \cdot t_{i} 13\right)
$$

- from the equation (13) calculated were the values for ori and are depicted in Table 2. Necessary sums for the system of normal equations were made on the basis of the experimental results and are depicted in Table 2.

- standard deviation was calculated from the equation (4): $s_{i}=0.6878$

- Linear correlation coefficient between oi and pi was calculated by equation (6):

$$
\begin{aligned}
& r_{12}=0.4128 \\
& r_{13}=0.78 \\
& r_{23}=0
\end{aligned}
$$

- standard estimation error was calculated from the equation (7): $S_{1.23}=0.3227384$

- the linear multiple correlation coefficient of $\sigma i$ by pi and ti were calculated from the equation (8): $R_{1.23}=0.8824$

- multiple determination coefficients were calculated from the equation (9):

$$
R_{1.23}^{2}=0.7788
$$

- The linear partial correlation coefficients were calculated from the equation (10):

$$
\begin{aligned}
& r_{12.3}=0.497 \\
& r_{13.2}=0.9402 \\
& r_{23.1}=-0.99
\end{aligned}
$$

\section{DISCUSSION}

Elastomer extrusion continual technological process is specific and complex. Technological process, under working conditions, can be obtained after laboratory investigations and examinations. Variable elements during the technological process are chosen to produce the extruded product with satisfactory quality. Working conditions were chosen in a narrow range and are described in the experimental part (Table 1).

Mathematical interpretation of the results started from the hypothesis that there is a linear dependence between the technological process characteristics. Using the described theory of linear dependence obtained was the equation (13). From the linear regression equation (13) observed can be that the pressure factor influences more mechanical characteristics of the extruded elastomer than the vulcanization time, for the chosen working conditions. The coefficient of the multiple determination, which is the square value of the multiple correlation coefficient, indicated that $78 \%\left(\mathrm{R}^{2}{ }_{12.3}=0.7788\right)$ of the whole variation in $\sigma i$ is explained with the regression equation. From the value of the linear partial correlation coefficient by equation (10) follows that it is more desirable to keep pressure constant and choose the vulcanization time. When the vulcanization pressure (pi) is kept at the constant level and vulcanization time is chosen, then in $94 \%$ of the cases, obtained can be desired product's isolation tensile strength. In the case when vulcanization time is kept constant and pressure is changed, in $50 \%$ of the cases, obtained can be the desired elastomer tensile strength. From the linear partial correlation coefficient pressure factors and time $\left(p_{i}\right.$ and $\left.t_{i}\right)$ obtained can be the value $r_{23.1}=-0.99$ which indicated the strong factors' interactions which are with the opposite effect.

Results presented in the Table 3, are calculated values for all possible variants values influencing the technological process and their influence on mechanical characteristics of the extrudate rubber isolation. It is possible to conclude that when the pressure is kept constant and the vulcanization time is changed the tensile strength decreases for infinitesimal, but constant value, $\Delta \sigma_{i}=2.2 \mathrm{~Pa}$ and graphical interpretation of the function gave three linear curves which overlay. In the second variant, for all the values when the vulcanization time is kept constant and with the vulcanization pressure increasing observed was the increase in tension for remarkable and constant value of $\Delta \sigma_{i}=254 \mathrm{~Pa}$. The results obtained are logical and expected, indicating that the process factors order range was well chosen.

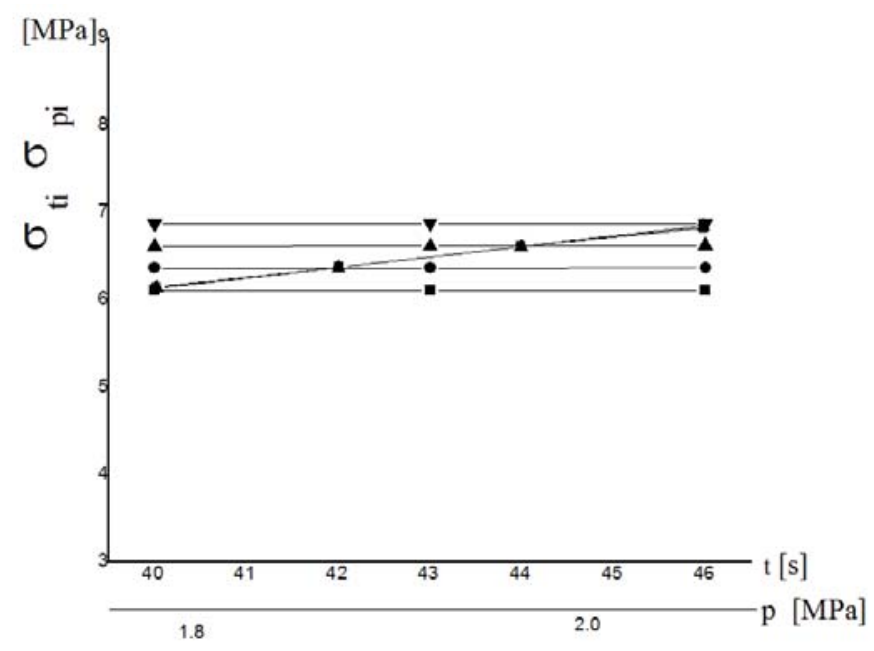

Figure 2: Graphical interpretation of pressure and vulcanization time dependence 
Table 3: Results for pressure and velocity

\begin{tabular}{|c|c|c|c|c|c|c|}
\cline { 2 - 7 } \multicolumn{1}{c|}{} & \multicolumn{3}{c|}{$\sigma p i$} & \multicolumn{3}{c|}{$\sigma t i$} \\
\hline $\mathrm{p} 1$ & $\mathrm{p} 2$ & $\mathrm{p} 3$ & $\mathrm{p} 4$ & $\mathrm{t} 1$ & $\mathrm{t} 2$ & $\mathrm{t} 3$ \\
\hline 6.1111 & 6.3654 & 6.6197 & 6.8740 & 6.1111 & 6.1089 & 6.1068 \\
\hline 6.1089 & 6.3632 & 6.6176 & 6.8719 & 6.3654 & 6.3632 & 6.3611 \\
\hline 6.1068 & 6.3611 & 6.6154 & 6.8697 & 6.6197 & 6.6176 & 6.6094 \\
\hline
\end{tabular}

\section{CONCLUSION}

It can be drawn that the aim of the work was fully realized. From the results presented it can be concluded that it is desirable and necessary to interpret and analyze mathematically the production processes. It was achieved to keep the production process within the desired limits and to have an insight in the technological process conditions.

\section{REFERENCES}

1. Baldwin, F. P., ver Strate, G., (1972) Polyolefin elastomers of ethylene and propylene, Rubber Chem. Technol., 45, $709-881$.

2. DIN VDE0282-1: Starkstromleitungen mit vernetzter Isolierhuelle fuer Nennspannungen bis 450/750V-Teil 1: allgemeine Anforderungen; Deutsche Fassung HD 22.1 S4: 2002 (2003-09).

3. Gent, A. N. (1978) Science and Technology of Rubber, New York: Academic Press.

4. Hadživuković, S. (1991) Statistički metod, Novi Sad: Poljoprivredni fakultet.

5. Kosar, V., Gomzi, Z., (2007). Modeling of the power cable production line, Thermochimica Acta, 457, 70 $-82$.

6. ISO 1421: Rubber- or plastics-coated fabrics Determination of tensile strength and elongation at break (1998).

7. Lenir, V. L. (1984) Computerization of wire insulating lines. An industrial approach, Polym.Eng.Sci., 24 (9), $633-644$

8. Malić, D. (1963) Termodinamika, termotehnika, Beograd: Građevinska knjiga.

9. Mandić, J. (1992) Otpornost materijala, Beograd: Naučna knjiga.

10. Milani, G., Milani, F. (2008). Genetic algorithm for the optimization of rubber insulated high voltage power cables production lines, Computers and Chemical Engineering, 32, $3198-3212$.

11. Pantelić I. (1976) Uvod u teoriju inženjerskog eksperimenta, Novi Sad: Radnički Univerzitet „Radivoj Ćirpanov".
12. Рябинин, Д. Д., Лукач, Ю.Е (1965) Червячные машины для переработки пластических масс, Москва: Машиностроение.

13. Roberts, B.E., Verne, S. (1984) Industrial applications of different methods of cross-linking polyethylene, Plast. Rubber Process Appl., 4 (2), 135 - 139.

14. Schwarr, R. H., Chien, C. H. (1981) Ethylene-propylene co and ter polymer rubber, Report 4b, Menlo Park, CA: Stanford Research Institute.

15. Seymour, V., Gomzi, Z. (2007) Modeling of the power cable production line, Thermochim Acta, 457, 70 -82 .

16. Tabak, V. (1990) Linija za kontinualnu vulkanizaciju, Deveti dani Društva plastičara i gumaraca, Zagreb.

17. Tehnička dokumentacija: Organizacija i način rada ulazne kontrole gumarskih materijala, Novi Sad: Fabrika "Novkabel”.

18. Vukadinović, S. (1978) Elementi teorije verovatnoće i matematičke statistike, Beograd: Privredni pregled.
Paper submitted: 29.06.2017.

Paper accepted: 13.11.2017.

This is an open access article distributed under the CC BY-NC-ND 4.0 terms and conditions. 